\title{
Antigammaglobulin (rheumatoid factor) activity of human IgG subclasses
}

\author{
F. SHAKIB AND D. R. STANWORTH
}

From the Department of Experimental Pathology, Birmingham University Medical School, Birmingham B15 $2 T$ द्धि

SUMMARY. A sensitive radioimmunoassay has been applied to the study of rheumatoid factoge activity of IgM and IgG subclasses in serum and synovial fluid of patients with rheumatoid arthritiș Although rheumatoid factor activity was found in all four subclasses, its distribution was not the् same as that of the total subclasses in normal sera. Results are discussed in relation to the possible clinical value of measuring IgG rheumatoid factor in sera and synovial fluids of patients wit $\underline{\underline{n}}$ rheumatoid arthritis.

Antigammaglobulins, known collectively as rheumatoid factors, are predominantly of the IgM class. IgG rheumatoid factors are also known to be present in the serum of rheumatoid arthritis patients (Torrigiani and Roitt, 1967; Ilter and Turner, 1973; Abruzzo and Heimer, 1974a, b; Hay et al., 1975) and these, like IgM rheumatoid factor, could be involved in the formation of deleterious antigenantibody complexes which contribute to the induction of inflammatory reactions in the joints. Such antigammaglobulins of the IgG class have been shown in rheumatoid arthritis sera by adsorption onto an insolubilised (heat aggregated or chemicallycross-linked) rabbit IgG, followed by elution at low $\mathrm{pH}$ and quantitation by radial immunodiffusion (Torrigiani and Roitt, 1967; Ilter and Turner, 1973; Okafor, et al., 1975) or latex agglutination assay (Abruzzo and Heimer, 1974a, b).

In a previous report (Shakib and Stanworth, 1976) we showed, using specific antisera in a radial immunodiffusion system, that IgG representative of all four subclasses is present in rheumatoid synovial fluids in a proportion similar to that in the corresponding sera. In order to obtain further information about the possible roles of immunoglobulin of the IgG class in the joint of rheumatoid patients, a sensitive radioimmunoassay has now been used to measure specific anti-IgG antibody activity within those IgG subclasses detectable in synovial fluids and sera.

\section{Materials and methods}

RHEUMATOID SYNOVIAL FLUIDS AND SERA Serum samples were obtained from 117 adult patients (50 seropositive, 67 seronegative) 惯施 rheumatoid arthritis, of whom 28 patients 114 seropositive, 14 seronegative) also providede specimen taken concomitantly of synovial fluid frorm the knee. All samples (sera and joint fluids) were decomplemented by heating at $56^{\circ} \mathrm{C}$ for 30 minutes before testing for rheumatoid factor activity in the Rose-Waaler system.

NONRHEUMATOID SYNOVIAL FLUIDS AND SER Nonrheumatoid control samples comprised three matched pairs of serum and knee synovial fluię taken from adult patients with osteoarthrosis, $1 \not{Q}$ serum specimens from healthy young adults, an one knee joint fluid sample from a healthy young adult female.

MEASUREMENT OF THE ROSE - WAALER TITRE The Rose-Waaler titre of the rheumatoid samples were measured by the standard procedure of Roseet al. (1948) and Waaler (1940), using sheep erythroo cytes sensitised with a subagglutinating dose of rabbit antisheep erythrocyte antibody.

HYALURONIDASE TREATMENT OF SYNOVIAL FLUIDS

To $1 \mathrm{ml}$ of synovial fluid, $0.05 \mathrm{ml}$ of hyaluronidas enzyme (Koch-Light Laboratories Ltd) solution (made up by suspending $0.1 \mathrm{mg}$ of the enzyme in $10 \mathrm{ml}$ of $0.075 \mathrm{M}$ sodium phosphate buffer, $\mathrm{pH} 7 \cdot{ }^{\circ}$ 
containing $0.075 \mathrm{M}$ sodium chloride) was added and the mixture incubated at $37^{\circ} \mathrm{C}$ for 60 minutes.

\begin{abstract}
ASSAY OF ANTIGAMMAGLOBULIN ACTIVITY
The method used for measuring rheumatoid factor activity of IgM, IgG, and IgG subclasses is a modification of that described by Hay et al. (1975) for measuring antigammaglobulin activity of IgM and total IgG in rheumatoid arthritis sera.
\end{abstract}

\section{(a) Coating the tubes with rabbit IgG}

One $\mathrm{ml}$ volumes of $0.01 \mathrm{~g} / \mathrm{l}$ of rabbit IgG in phosphate buffered saline (PBS; $0.01 \mathrm{M} \mathrm{PO}_{4}, \mathrm{pH} \mathrm{7.2}$ containing $0.15 \mathrm{M} \mathrm{NaCl}$ ) were incubated in $2.5 \mathrm{ml}$ plastic tubes of $8 \mathrm{~mm}$ diameter (Luckham Ltd, Victoria Gardens, Sussex) for one hour at room temperature and then overnight at $4^{\circ} \mathrm{C}$. The IgG solution was then discarded and the tubes washed three times with PBS. Sites on the tube surface left unoccupied by rabbit IgG were blocked by subsequently incubating $2 \mathrm{ml}$ of bovine serum albumin (BSA) solution ( $10 \mathrm{~g} / 1$ in PBS) in the tubes for 2 hours at room temperature. The BSA solution was then discarded and the tubes washed three times with PBS, stoppered, and stored at $4^{\circ} \mathrm{C}$ until used for testing.

\section{(b) Preparation of the radiolabelled antisera}

Human IgG subclass specific antisera were raised in sheep as described previously (Shakib et al., 1975). Antisera to human IgM and to human IgG $(\gamma \mathrm{Fc})$ were prepared in rabbits using conventional immunisation schedules.

Antisera specific for IgM, IgG, and individual IgG subclasses, after being diluted and made equipotent, were each precipitated (from $1 \mathrm{ml}$ volume) by adding, dropwise with stirring, $2 \mathrm{ml}$ of $24 \% \mathrm{Na}_{2} \mathrm{SO}_{4}$ solution. The mixture was left standing for 15 minutes at room temperature whereupon the precipitate was separated by centrifugation and the supernatant discarded. The precipitate was finally dissolved in $1 \mathrm{ml}$ of saline-citrate buffer $(1.01$ aqueous solution containing $5.75 \mathrm{~g}$ trisodium citrate $2 \mathrm{H}_{2} \mathrm{O}, 27.25 \mathrm{~g} \mathrm{NaCl}$, and $0.5 \mathrm{ml}$ $1 \mathrm{~N} \mathrm{HCl}$ ), $\mathrm{pH} 7 \cdot 0$, and dialysed against the same buffer overnight at $4^{\circ} \mathrm{C}$.

This antibody-rich solution was radioactively labelled as described by Hawker and Hawker (1976). $30 \mu \mathrm{l}$ of the antibody solution was made up to $750 \mu \mathrm{l}$ with saline-citrate buffer, $\mathrm{pH} 7 \cdot 0$, placed in a flat bottomed disposable container (Luckhams, PT/ 1054) and stirred in an ice bath using a magnetic flea. $50 \mu \mathrm{l}$ (i.e. $200 \mu \mathrm{Ci}$ of activity) of suitably diluted ${ }^{125} \mathrm{I}\left(\mathrm{Na}{ }^{125} \mathrm{I}\right.$, IMS 30, Radiochemical Centre, Amersham) was added to the solution containing the antibody while stirring. To this $50 \mu$ l of freshly prepared chloramine- $T$ solution $(2 \mathrm{~g} / \mathrm{l})$ was added, rapidly with stirring, from an Eppendorf pipette followed after 2 minutes by $50 \mu \mathrm{l}$ of $\mathrm{Na}_{2} \mathrm{~S}_{2} \mathrm{O}_{5}(4 \mathrm{~g} / \mathrm{l})$. After a further 3 minutes of stirring, $100 \mu l$ of $17 \mathrm{~g} / 1$ aqueous KI was added. Any free iodide left in the solution was then separated from the labelled material in an especially designed apparatus (Hawker, 1974) which combines centrifugal desalting (through a column of Sephadex G-25 medium, packed in a disposable $10 \mathrm{ml}$ syringe barrel) and sterilisation (in a modified millipore filter unit attached to the syringe barrel).

\section{(c) Detection of antigammaglobulin activity}

To each rabbit IgG coated plastic tube, $450 \mu \mathrm{l}$ of $10 \mathrm{~g} / \mathrm{l}$ of BSA/PBS solution was added, as a diluent, followed by $50 \mu \mathrm{l}$ of the test or reference sample. The tubes were then incubated for 1 hour at $37^{\circ} \mathrm{C}$ and for half an hour at $4^{\circ} \mathrm{C}$. After the incubation period, the solutions were discarded and the tubes washed three times with cold PBS. One $\mathrm{ml}$ of $10 \mathrm{~g} / \mathrm{l}$ BSA/PBS solution containing $5 \mu l$ of the appropriate labelled antibody solution, was added to each tube and the tubes were incubated for 2 hours at $37^{\circ} \mathrm{C}$ and for half an hour at $4^{\circ} \mathrm{C}$. The radioactive solutions were then discarded and the tubes washed three times with cold PBS. The tubes were drained free of any liquid and counted in a gamma-ray counter (Tracerlab gamma/guard 150) for 50 seconds. All samples were assayed in duplicate.

'Rheumatoid factor activity' of serum IgM, IgG, and of each IgG subclass was expressed as a ratio of the test serum counts $/ 50 \mathrm{~s}$ to the mean counts $/ 50 \mathrm{~s}$ of a group of normal sera (10 samples); the ratio being referred to as 'rheumatoid factor index' (RFI). The rheumatoid factor activity of IgM and IgG of synovial fluid was expressed similarly by taking the ratio of the test sample counts $/ 50$ s to that of a normal synovial fluid.

\section{(d) Nonspecific adsorption of antisera on to the tube surface}

The nonspecific adsorption of the radioactively labelled antibodies onto the plastic tube surface was assessed by incubating $1 \mathrm{ml}$ of $10 \mathrm{~g} / 1$ BSA/PBS solution containing $5 \mu \mathrm{l}$ of the appropriate labelled antibody solution in rabbit IgG coated tubes which had not been first treated with test samples. The adsorption (measured as radioactive counts $/ 50 \mathrm{~s}$ ) of each of the anti-IgM, anti-IgG (total), and anti-IgG subclass specific antisera onto the plastic tube surface was negligible (i.e. between 117-397 counts/ $50 \mathrm{~s})$ when the tubes were not first treated with a test sample. 
(e) Nonspecific adsorption of test serum and synovial fluid antibodies onto the tube surface

This was assessed by first treating with BSA instead of rabbit IgG, then coating the tubes with a test sample followed finally by treatment with ${ }^{125} \mathrm{I}$ labelled antiserum as described in (c). The binding of serum IgM, IgG (total), and each of IgG subclasses, as indicated in this way by the adsorption of their respective specific ${ }^{125}$ I-labelled antisera (measured as counts $/ 50 \mathrm{~s}$ ) to BSA coated tube surface, was negligible (i.e. between 112-231 counts $/ 50 \mathrm{~s}$ ).

\section{(f) Specificity of the antisera}

The specificity of the antisera used in the present radioimmunoassay system was assessed by incubating, as described in (c), $1 \mathrm{ml}$ of $10 \mathrm{~g} / 1 \mathrm{BSA} / \mathrm{PBS}$ solution containing $5 \mu \mathrm{l}$ of the appropriate labelled antibody solution in each of 6 tubes coated with myeloma IgM, IgG (total), IgG1, IgG2, IgG3, and IgG4 respectively and blocked with BSA. Such experiments have shown (Table 1) that the anti-IgM, anti-IgG (total), and anti-IgG subclass specific antisera were all highly monospecific and strongly reactive with the respective immunoglobulin class or subclass.

Table 1 Specificity of the antisera used in the radioimmunoassay of antigammaglobulin activity

\begin{tabular}{lrrrrrr}
\hline Antiserum & \multicolumn{3}{l}{$\begin{array}{l}\text { Amount of radioactivity } \\
\text { coated with pure: }\end{array}$} & (counts/50 s) & bound to tubes \\
\cline { 2 - 7 } & IgM & IgG & IgGI & $I g G 2$ & $I g G 3$ & $I g G 4$ \\
\hline Anti-IgM* & 4246 & 193 & 217 & 173 & 302 & 121 \\
Anti-IgG* & 203 & 5303 & 4893 & 4010 & 5197 & 4098 \\
Anti-IgG1 & 163 & 7652 & 7983 & 316 & 273 & 188 \\
Anti-IgG2 & 125 & 3930 & 223 & 3750 & 163 & 211 \\
Anti-IgG3 & 198 & 5016 & 312 & 208 & 4737 & 207 \\
Anti-IgG4 & 221 & 3981 & 353 & 312 & 275 & 4431 \\
\hline
\end{tabular}

*These antisera were raised in rabbits

\section{Results}

EFFECT OF HYALURONIDASE TREATMENT OF ANTIGAMMAGLOBULIN ACTIVITY MEASUREMENT IN SYNOVIAL FLUIDS

In a previous report (Shakib and Stanworth, 197@ we showed that the rather high viscosity of synovial fluid does not interfere with the measurement of is IgG concentration by radial immunodiffusion. Tha such a high viscosity could interfere with the measurement of antigammaglobulin activity in synovial fluids by means of the present radio immunoassay sytsem was investigated by treatin $\overrightarrow{\vec{s}}$ five synovial fluid samples with hyaluronidase for 60 minutes at $37^{\circ} \mathrm{C}$. RFI values of IgiM, IgG (total and IgG subclasses of the five samples were dete $E_{3}$ mined before and after treatment with hyaluronidase. In order to eliminate the 'between batch' variation of the method, both treated and untreated samples were assayed in the same batch. The difference between each pair of results, i.e. before and after hyaluronidase treatment, was found to be within the 'within batch' variation of the antigammaglobulio assay (Table 2).

ANTIGAMMAGLOBULIN ACTIVITY STUDIESOI $\vec{\oplus}$ NORMAL INDIVIDUALS

The RFI of the IgM, IgG (total), and IgG subclass of the sera of 10 normal individuals was determinges by dividing the RF activity of each sample, expresse as counts $/ 50 \mathrm{~s}$, by the mean RF activity (i.e. meas counts $/ 50 \mathrm{~s}$.) of the 10 normal sera. The ranges 8 RFI found in the sera of 10 healthy adults are give in Table 3.

Because there was only one normal synoviat fluid sample available in hand, the normal variatio of the RFI in synovial fluid was calculated by assay ing the normal synovial fluid ten times for $R \bar{E}$ activity of IgM, IgG (total), and IgG subclasses. 面 each case the RFI was determined by taking the ratio of individual results, expressed as counts $/ 50$ \&

Table 2 Effect of hyaluronidase treatment on antigammaglobulin activity measurement in synovial fluid

\begin{tabular}{|c|c|c|c|c|c|c|c|c|c|c|c|c|}
\hline \multirow{3}{*}{ Specimen no. } & \multicolumn{12}{|c|}{ Rheumatoid factor index of } \\
\hline & \multicolumn{2}{|l|}{$I g M$} & \multicolumn{2}{|l|}{$I g G$} & \multicolumn{2}{|l|}{$I g G I$} & \multicolumn{2}{|l|}{$I g G 2$} & \multicolumn{2}{|c|}{ IgG3 } & \multicolumn{2}{|c|}{$I g G 4$} \\
\hline & $A$ & $\boldsymbol{B}$ & $\boldsymbol{A}$ & $\boldsymbol{B}$ & $A$ & $\boldsymbol{B}$ & $\boldsymbol{A}$ & $\boldsymbol{B}$ & $A$ & $\boldsymbol{B}$ & $A$ & $\boldsymbol{B}$ \\
\hline $\begin{array}{l}1 \\
2 \\
3 \\
4 \\
5\end{array}$ & $\begin{array}{l}1.63 \\
2.18 \\
2.45 \\
2.89 \\
1.95\end{array}$ & $\begin{array}{l}1 \cdot 56 \\
2 \cdot 31 \\
2 \cdot 19 \\
2 \cdot 77 \\
2 \cdot 09\end{array}$ & $\begin{array}{l}1.26 \\
1.74 \\
1.64 \\
1.40 \\
1.41\end{array}$ & $\begin{array}{l}1 \cdot 37 \\
1.85 \\
1.53 \\
1.30 \\
1.52\end{array}$ & $\begin{array}{l}1.08 \\
1.32 \\
1.09 \\
1.26 \\
1.23\end{array}$ & $\begin{array}{l}1 \cdot 00 \\
1 \cdot 15 \\
1 \cdot 19 \\
1.43 \\
1 \cdot 11\end{array}$ & $\begin{array}{l}1.48 \\
1 \cdot 72 \\
1 \cdot 23 \\
1 \cdot 18 \\
1.44\end{array}$ & $\begin{array}{l}1 \cdot 18 \\
1.64 \\
1 \cdot 30 \\
1.05 \\
1.30\end{array}$ & $\begin{array}{l}1.41 \\
1.72 \\
1.56 \\
1.23 \\
1.20\end{array}$ & $\begin{array}{l}1.57 \\
1.49 \\
1.69 \\
1.38 \\
1.25\end{array}$ & $\begin{array}{l}1.49 \\
1.75 \\
1.31 \\
1.59 \\
1.49\end{array}$ & $\begin{array}{l}1 \cdot 53 \\
1 \cdot 72 \\
1 \cdot 47 \\
1 \cdot 71 \\
1 \cdot 24\end{array}$ \\
\hline
\end{tabular}


Table 3 Rheumatoid factor activity of $\operatorname{IgM}, \mathrm{IgG}$, and IgG subclasses detectable in sera and synovial fluids of patients with rheumatoid arthritis, osteoarthrosis $(O A)$, and of normal individuals

\begin{tabular}{|c|c|c|c|c|c|c|c|c|c|c|c|c|c|c|}
\hline \multirow[t]{3}{*}{ Group } & \multirow{3}{*}{$\begin{array}{l}\text { Type of } \\
\text { material } \\
\text { studied }\end{array}$} & \multirow{3}{*}{$\begin{array}{l}\text { No. of } \\
\text { individuals } \\
\text { studied }\end{array}$} & \multicolumn{12}{|c|}{ Rheumatoid factor index of } \\
\hline & & & \multicolumn{2}{|l|}{$I g M$} & \multicolumn{2}{|l|}{ IgG } & \multicolumn{2}{|l|}{$I g G I$} & \multicolumn{2}{|l|}{$I g G 2$} & \multicolumn{2}{|l|}{$I g G 3$} & \multicolumn{2}{|l|}{$\operatorname{IgG4}$} \\
\hline & & & Mean & Range & Mean & Range & Mean & Range & Mean & Range & Mean & Range & Mean & Range \\
\hline \multirow[t]{2}{*}{$\mathbf{R A}(+)$} & $S$ & 50 & $3 \cdot 79$ & $1 \cdot 29-5 \cdot 73$ & 1.47 & $0 \cdot 87-2 \cdot 14$ & $1 \cdot 33$ & 0.81 & $1 \cdot 13$ & $0.71-1.92$ & 0.88 & 0.52 & $1 \cdot 21$ & 0.71 \\
\hline & SF & 14 & $2 \cdot 17$ & $1.61-2.60$ & $2 \cdot 07$ & $1.52-2.80$ & 1.75 & $1 \cdot 32$ & 1.44 & 0.88 & $1 \cdot 34$ & 14 & 1.71 & $1 \cdot 2$ \\
\hline \multirow[t]{2}{*}{$\mathbf{R A}(-)$} & $\mathbf{S}$ & 67 & 1.90 & $0.93-3.70$ & $1 \cdot 26$ & $0.72-1.96$ & 0.98 & $0.72-1.48$ & 1.06 & $0 \cdot 73-1 \cdot 70$ & 0.80 & $0.50-1.53$ & 0.95 & $0.70-1.57$ \\
\hline & SF & 14 & 1.45 & $0.68-2.20$ & $2 \cdot 10$ & $1.50-2.51$ & 1.44 & $1 \cdot 10-2 \cdot 13$ & 1.59 & $1.21-2.09$ & $1 \cdot 25$ & $0.86-1.68$ & 1.27 & $0.96-1.85$ \\
\hline \multirow[t]{2}{*}{ OA } & $\mathbf{S}$ & 3 & 0.89 & $0.75-1.00$ & 0.81 & $0.77-0.90$ & 0.96 & $0.88-1.01$ & 0.83 & $0.79-0.87$ & 0.97 & $0.93-1.01$ & 1.04 & $1.01-1.08$ \\
\hline & SF & 3 & 0.99 & $0.72-1.43$ & 1.00 & $0.89-1.08$ & 0.96 & $0.94-1.00$ & 1.00 & $0.96-1.03$ & 0.97 & $0.96-1.00$ & 0.95 & $0.94-0.06$ \\
\hline \multirow[t]{2}{*}{ Normal } & $\mathbf{S}$ & 10 & $1 \cdot 10$ & $0.65-1.73$ & 1.01 & $0 \cdot 83-1 \cdot 18$ & 0.99 & $0 \cdot 75-1 \cdot 24$ & 0.93 & $0 \cdot 70-1 \cdot 26$ & 0.97 & $0 \cdot 8-1 \cdot 19$ & 0.99 & $0 \cdot 82-1 \cdot 18$ \\
\hline & SF & 1 & 1.00 & $0.38-1.23$ & 1.00 & $0 \cdot 78-1 \cdot 17$ & 1.00 & $0 \cdot 73-1 \cdot 22$ & 1.00 & $0 \cdot 63-1 \cdot 13$ & 1.00 & $0.75-1.20$ & 1.00 & $0.67-1 \cdot 18$ \\
\hline
\end{tabular}

*S = serum; $\mathbf{S F}=$ synovial fluid.

to the mean of the 10 results (i.e. mean counts $/ 50 \mathrm{~s}$ ). The upper and lower limits of RFI variation for each of the immunoglobulins studied in the normal synovial fluid are given in Table 3.

STUDIES OF ANTIGAMMAGLOBULIN ACTIVITY IN SEROPOSITIVE RHEUMATOID PATIENTS

The assay of RF activity was performed on 50 sera and 14 synovial fluids obtained from 50 seropositive rheumatoid patients. Results are summarised in Table 3. Abnormally high IgM and IgG RFI values were found in the sera of $48(96 \%)$ and $42(84 \%)$ seropositive rheumatoid patients respectively. The IgG subclass distribution of RF activity did not reflect the relative proportion of these subclasses in normal sera studied previously (Shakib et al., 1975); abnormally high IgG1, IgG2, IgG3, and IgG4 RFI values were found in $31(62 \%), 13(26 \%), 2(4 \%)$, and $24(48 \%)$ seropositive patients respectively.

Abnormally high values of IgM and IgG RFI were found in all synovial fluid specimens taken from 14 seropositive rheumatoid patients. The IgG subclass distribution of RF activity in the synovial fluid samples was, on the whole, different from that found in the corresponding sera. Thus, RFI values of IgG1, IgG2, IgG3, and IgG4 were abnormally high (in comparison with levels found in just one normal synovial fluid) in $14(100 \%), 10(71 \%), 6$ $(43 \%)$, and $14(100 \%)$ rheumatoid synovial fluid specimens respectively.

Regression analysis of data showed no correlation between values of RFI of IgM, IgG (total), and IgG subclasses in rheumatoid synovial fluids and the values found in the corresponding sera.

STUDIES OF ANTIGAMMAGLOBULIN ACTIVITY IN SERONEGATIVE RHEUMATOID PATIENTS

The assay of RF activity was performed on 67 sera and 14 synovial fluids obtained from 67 seronegative rheumatoid patients. Results are summarised in Table 3. Out of 67 seronegative rheumatoid sera, 36 (54\%) had IgM RFI values which were higher than the upper limit of normal but these IgM RFI values were significantly lower $(P<0.001)$ than those found in the sera of seropositive patients. High serum IgG RFI values were also found in $36(54 \%)$ rheumatoid patients (only some of whom also showed high IgM RFI values) but the values appeared to be similar to those found in the sera of seropositive rheumatoid patients.

The IgG subclass distribution of RF activity in the sera of seronegative patients was different from that in the seropositive patients' sera. Thus abnormally high RFI values of IgG1, IgG2, IgG3, and IgG4 were found in only 3 (4\%), 11 (16\%), 3 (4\%), and $2(3 \%)$ seronegative patients respectively; values being significantly lower $(P<0 \cdot 1-0.001)$ than those of the seropositive patients' sera.

Abnormally high values of IgM and IgG RFI were found in $10(71 \%)$ and $14(100 \%)$ synovial fluid samples from seronegative patients respectively; the IgM RFI values being significantly lower $(P<0.001)$ than those found in seropositive rheumatoid patients. The IgG subclass distribution of RF activity in the synovial fluid samples of seronegative rheumatoid patients was found to be different from that found in synovial fluid samples of seropositive patients. Thus RFI values of IgG1, IgG2, IgG3, and IgG4 were abnormally high in 13 (93\%), 14 (100\%), $7(50 \%)$, and $8(57 \%)$ synovial fluid specimens of seronegative patients respectively; only IgG1 $(P<0.01)$ and IgG4 $(P<0.001)$ RFI values being significantly lower than those of seropositive patients.

Regression analysis showed no correlation beween the values of RFI of IgG (total) and IgG subclasses in synovial fluids and the values found in the corresponding sera from seronegative patients, IgM RFI values showing a correlation coefficient of 0.91 . 
ANTIGAMMAGLOBULIN ACTIVITY STUDIES IN OSTEOARTHROTIC PATIENTS

RF activity was also determined in sera and synovial fluids taken concurrently from 3 patients with osteoarthrosis. All showed normal IgM and IgG RFI values in their serum and synovial fluid samples except for one who showed an abnormally high IgM RFI value in the synovial fluid sample, but not in the serum. The results are summarised in Table 3.

\section{Discussion}

Rheumatoid factor activity of the IgG class has previously been shown by adsorption on to, and elution from, cross-linked IgG followed by quantitative radial immunodiffusion (Torrigiani and Roitt, 1967; Ilter and Turner, 1973; Okafor et al., 1975) or semiquantitative latex agglutination assay (Abruzzo and Heimer, 1974a, b). Such methods, in addition to being very laborious, are not applicable to the measurement of RF activity within the IgG subclasses, mainly because of their poor sensitivity. The present radioimmunoassay, which was previously applied to the measurement of RF activity of serum IgM and total IgG (Hay et al., 1975), has proved satisfactory for studying the RF activity within IgG subclasses. The sensitivity of the technique is such that $\mathbf{4 0 0}$ specimens can be assayed using as little as $30 \mu l$ of antiserum.

Using this method, abnormally high IgM RFI values were found in almost all seropositive and in about $50 \%$ of sera from seronegative rheumatoid arthritis patients, levels found in seronegative patients being significantly lower $(\mathrm{P}<0.001)$ than those in seropositive patients. Thus the apparent absence of RF activity reported in a certain proportion of rheumatoid patients (consequently referred to as seronegative) is probably due to the use of the relatively insensitive Rose-Waaler haemagglutination assay. Moreover, it is of interest in this connection that regression analysis of the IgM RFI values, found in sera of seropositive patients, showed no correlation with RF activity values as measured by the conventional Rose-Waaler technique; an observation which could suggest that these two assay systems are measuring a different facet of the RF activity. In the Rose-Waaler haemagglutination assay one is measuring only 19S RFs which are capable of agglutinating (i.e. pentameric IgM) red cells coated with rabbit IgG. Whereas the radioimmunoassay technique could, theoretically, be measuring all IgM RFs that can bind to rabbit IgG-coated plastic tube surface, in other words the latter technique is capable of measuring both pentameric and monomeric (7S) IgM RF. Indeed 7S IgM RFs, which can also fix complement
(Augener et al., 1971), are known to be present i rheumatoid arthritis sera and joint fluids.

Furthermore, although most of the serum RE. activity is of the IgM class, IgG RF could also be involved in the formation of deleterious antigen $?$ antibody complexes which contribute to the ir flammatory changes of the joints. Thus IgG RFI values were abnormally high in $100 \%$ of the synoviaf fluid specimens of the seronegative (as well as seropositive) rheumatoid patients, suggesting that $\%$ more complete evaluation of rheumatoid patients. should also include looking for RF activity of the IgM and IgG classes at sites of the discomfor (i.e. affected joints). Such observations woule possibly favour the use of the radioimmunoassay as a more reliable alternative to the Rose-Waaleit haemagglutination technique for assessing the $R F^{N}$ activity in the rheumatoid sera and synovial fluids. The ultimate aim would be to abandon the term seropositive and seronegative rheumatoid patients and instead to consider rheumatoid arthritis as $\vec{a}$ disease which can manifest itself at different levels oo severity.

Many patients, both seropositive and seronega tive, showed abnormally high serum IgG RFL values, mainly of the IgG1 (abnormally high in $68 \%$ of patients) and IgG4 (abnormally high in $48 \% 0 .{ }^{\circ}$

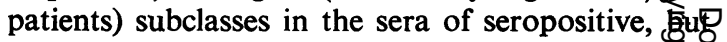
not seronegative, rheumatoid patients. RF activities of the IgG2 and IgG3 subclasses, on the other hand were rarely demonstrable in the sera of the rheuma toid patients; in fact IgG3 RF activity was found t $\$$ be lower than normal in many patients. A particu larly important finding was the existence in some patients of high IgG RFI values which could not beaccounted for by anti- $\gamma$ globulin activity in any of the known four subclasses of IgG. Thus in 22 sero negatives and 6 seropositives there were RF activi $\overline{0}$ ties of the IgG class which cannot be subclassed by any of the anti-IgG subclass antisera. It is notable. that the existence of a fifth IgG subclass has bee claimed by Spiegelberg (1973), who described $\vec{a}$ noncomplement-fixing human 7S myeloma proteif which could not be typed with antisera to known IgG subclasses.

Studies of the RF activity in synovial fluids of rheumatoid patients showed IgM RFI values to be abnormally high in all studies of seropositive patients, levels being significantly higher $(P<0.001 \mathrm{~W}$ than those found in seronegative patients. IgG RE activity was abnormally high in all synovial fluidb samples studied. The distribution of RF among the् IgG subclasses of rheumatoid synovial fluids was? found to be different from that in the sera, in thato RF activity of the IgG2 subclass, in addition to tha of IgG1 and IgG4, was abnormally high in many of 
the patients. Unlike IgG RFI, IgM RFI values were lower in the joint fluids than in the corresponding sera in both seropositive and seronegative rheumatoid patients, a finding which may indicate a preferential immune-elimination of complexes of the IgG-IgM type rather than of the IgG-IgG type from the rheumatoid arthritic joint. Such a preferential immune-elimination mechanism may also be responsible for the low IgG3 RF activity found in the rheumatoid synovial fluids and sera.

One other interesting aspect of this work was the demonstration that all four subclasses of human IgG possess RF activity, but their relative frequency of response could be dependent on the genetic constitution of the individual. Antibodies to other self antigens such as thyroglobulin (Hay and Torrigiani, 1973), glomerular basement membrane (Lewis et al., 1970; McPhaul and Dixon, 1971), and nuclear antigens (Tojo et al., 1970) have also been reported to occur in all IgG subclasses.

We thank Dr M. Shadforth and Mr R. A. Crockson for supplying the rheumatoid specimens.

\section{References}

Abruzzo, J. L., and Heimer. R. (1974a). IgG-anti-IgG antibody in rheumatoid arthritis and certain other conditions. Annals of the Rheumatic Diseases, 33, 258-261.

Abruzzo, J. L., and Heimer, R. (1974b). The measurement of IgG-anti-IgG antibody in rheumatoid arthritis. Journal of Immunological Methods, 4, 149-160.

Augener, W., Grey, H. M., Cooper, N. R., and MüllerEberhard, H. J. (1971). The reaction of monomeric and aggregated immunoglobulins with $\mathrm{Cl}$. Immunochemistry, 8, 1011-1020.

Hawker, R. J. (1974). Combined centrifugal desalting and sterilising apparatus. Laboratory Practice, 23, 651-652.

Hawker, R. J., and Hawker, L. (1976). A rapidly produced ${ }_{125}$ I labelled autologous fibrinogen. In vitro properties and preliminary metabolic studies in man. Journal of Clinical Pathology, 29, 495-501.

Hay, F. C., and Torrigiani, G. (1973). The distribution of anti-thyroglobulin antibodies in the immunoglobulin Gsubclasses. Clinical and Experimental Immunology, 15, 517-521.

Hay, F. C., Nineham, L. J., and Roitt, I. M. (1975). Routine assay for detection of IgG and IgM anti-globulins in seronegative and seropositive rheumatoid arthritis. British Medical Journal, 3, 203-204.

Ilter, O. D., and Turner, M. W. (1973). Determination of IgG-anti-globulins in rheumatoid disease using insolubilised human IgG. Clinical and Experimental Immunology, 15, 93-101.

Lewis, E. J., Busch, G. J., and Schur, P. H. (1970). Gamma G globulin subgroup composition of the glomerular deposit in human renal disease. Journal of Clinical Invstigation, 49, 1103-1113.

McPhaul, J. J., and Dixon, F. J. (1971). Characterisation of immunoglobulin $\mathbf{G}$ anti-glomerular basement membrane antibodies eluted from kidneys of patients with glomerulonephritis. II. IgG subtypes and in vitro complement fixation. Journal of Immunology, 107, 678-684.

Okafor, G. O., Turner, M. W., and Greenwood, B. M. (1975). Anti-globulins in Nigerians with rheumatoid disease. Annals of the Rheumatic Diseases, 34, 142-145.

Rose, H. M., Ragan, C., Pearce, E., and Lipman, M. O. (1948). Differential agglutination of normal and sensitised sheep erythrocytes by sera of patients with rheumatoid arthritis. Proceedings of the Society for Experimental Biology and Medicine, 68, 1-6.

Shakib, F., and Stanworth, D. R. (1976). IgG subclass composition of rheumatoid arthritic sera and joint fluids. Annals of the Rheumatic Diseases, 35, 263-266.

Shakib, F., Stanworth, D. R., Drew, R., and Catty, D. (1975). A quantitative study of the distribution of IgG subclasses in a group of normal human sera. Journal of Immunological Methods, 8, 17-28.

Spiegelberg, H. L. (1973). IgG5: studies of a myeloma protein of a new subclass. Federation Proceedings, 32, Abst. 4427.

Tojo, T., Friou, G. J., and Spiegelberg, H. L. (1970). Immunoglobulin $G$ subclass of human anti-nuclear antibodies. Clinical and Experimental Immunology, 6, 145-151.

Torrigiani, G., and Roitt, I. M. (1967). Anti-globulin factors in sera from patients with rheumatoid arthritis and normal subjects. Quantitative estimation in different immunoglobulin classes. Annals of the Rhcumatic Diseases, 26, 334-340.

Waaler, E. (1940). On the occurrence of a factor in human serum activating the specific agglutination of sheep blood corpuscle. Acta Pathologica et Microbiologica Scandinavica, 17, 172-188. 